\section{Identification and Quantification Methodology for the Analysis of Suspected Illegal Dietary Supplements: Reference Standard or no Reference Standard, that's the Question}

Celine Vanhee ${ }^{1 *}$, Emmy Tuenter ${ }^{2}$, Angelique Kamugisha', Michael Canfyn ${ }^{1}$, Goedele Moens ${ }^{1}$, Patricia Courselle ${ }^{1}$, Luc Pieters $^{2}$, Eric Deconinck ${ }^{1}$ and Vasiliki Exarchou ${ }^{2}$

\begin{abstract}
The consumption of food supplements has become a billion dollar business that has proliferated across the globe. Consequently this also resulted in the increase of adulterations by the illegal addition of medicinal substances or their analogues. The vast majority of the pharmaceutical substances encountered in those samples belong to the three 'classical' categories, including sexual enhancers (e.g. PDE-5 inhibitors and flibanserine), weight loss enhancers occasionally accompanied with an anti-depressant (e.g. sibutramine, phenolphthalein, sibutramine and fluoxetine or venlafaxine) and sports performance enhancers (e.g. selective androgen receptors (SARMs) and anabolic-androgenic steroids (AAS)). Recently also chemicals belonging to the class of pharmaceutical cognition enhancers or nootropics are gaining popularity amongst the general public. While for many of the classical categories reference standards are available to unambiguously confirm the identity of a pharmaceutical product, for several molecules, including some nootropics, no certified reference material is available. Hereby, with the example of an adrafinil containing food supplements, we show how, by utilising multiple methodologies, we were able to come to identification and subsequent quantification when no certified reference standard was available. Furthermore, in 2017 already several food supplements analysed by our lab were positive for the presence of nootropic substances, indicating that these compounds are really gaining popularity amongst the general public.
\end{abstract}

\section{Keywords}

Forensic chemistry; Adulterated food supplement; Mass spectrometry; Nuclear magnetic resonance; Counterfeit and illegal medicine; Synthetic cognition enhancer

\section{Introduction}

During the last decades the consumption of dietary supplements or food supplements has proliferated across the globe. A recent report

*Corresponding author: Celine Vanhee, Division of food, medicines and consumer safety, section medicinal products, Scientific Institute of Public Health (WIV-ISP), J.Wytsmansstraat14, B-1050 Brussels, Belgium; E-mail: celine.vanhee@wiv-isp.be

Received: August 02, 2017 Accepted: September 15, 2017 Published: September 19, 2017 showed that in the US dietary supplements are sold for more than $\$ 34$ billion a year [1]. Although many of these supplements contain only nutritional products, including vitamins and minerals, several reports have documented their adulteration with either pharmaceutical drugs approved by the FDA (U.S. Food and Drug Administration) and/or EMA (European Medicines Agency), non-approved medicine or medicine that has been taken off the market. The majority of these illegal substances found can be categorised as sexual performance enhancers, weight loss enhancers or sports performance enhancers [2]. These adulterated supplements could harbour severe risks for the oblivious consumer, in fact, one case with a lethal outcome has been reported in the scientific literature, where a natural health supplement contained a product termed 1,3-dimethylamylamine [3]. Furthermore, some research chemicals that did not undergo clinical testing or products for which only limited knowledge of their longterm toxicity is available, are sold via the internet as food supplements [4-11]. Therefore, several actions are on-going worldwide to protect the public from these malignant activities. Recently, the number of global and local inspections on food supplements has been increased and official controls in the respective chain are performed regularly [12]. In Belgium, the Federal Agency for the Safety of the Food Chain (FASFC) in collaboration with the Federal Agency for Medicines and Healthcare Products (FAMHP) and the federal law enforcement, are responsible for this task and upon their request questionable food supplements suspected to contain illegal pharmaceutical preparations or research chemicals are regularly subjected to analysis in our Official Medicines Control Laboratory (OMCL). As a standard approach followed in our laboratory, a suspicious pharmaceutical preparation or food supplement undergoes a screening study using two different destructive analytical methods, including gas chromatography-mass spectrometry (GC-MS) and liquid chromatography tandem-mass spectrometry (LC-MS/MS). By combining the outcome of these two methodologies, the identity of a molecule can be concluded from the obtained data in relation to the available certified reference material according to what has been described in the European council directive 96/23/EC [13]. However, this process becomes more challenging when no reference is available. Indeed, multiple methodologies were required to come to identification and subsequent quantification of the nootropic molecule adrafinil in a real life suspected illegal food supplement. Adrafinil, is a prodrug that is converted by hepatic metabolism to its active form modafinil. Modafinil and armodafinil, its enantiopure form, are registered medicines and in most countries their use requires a prescription. Adrafinil on the other hand, has been taken off the market, possibly as a result of the negative outcome of an investigation set out to analyse the benefits and hazards associated with this drug $[14,15]$. Although many food supplements containing adrafinil are currently still promoted online a natural health product, the world health organisation (WHO) recognises this molecule as anatomical therapeutic chemicals (ATC). In fact, Adrafinil, is classified in the group of psychostimulants, agents used for attention deficit hyperactivity disorder (ADHD) and nootropics (ATC code adrafinil: N06BX17). Furthermore according to the European directive, describing the definition of medicinal products and including borderline food products, this compound can be considered a medicinal product in the EU and therefore must apply to the legislation of medicinal product [16]. To this extent, Belgian 
Citation: Vanhee C, Tuenter E, Kamugisha A, Canfyn M, Moens G, et al.(2017) Identification and Quantification Methodology for the Analysis of Suspected Illegal Dietary Supplements: Reference Standard or no Reference Standard, that's the Question. J Forensic Toxicol Pharmacol 6:2.

law states that the use, purchasing and selling of food supplements containing this compound is illegal.

\section{Experimental}

\section{Chemicals and reagents}

Acetonitrile (UPLC/MS grade) and analytical grade formic acid, methanol and acetic acid were purchased from Biosolve (Valkenswaard, the Netherlands). Water was obtained using a milliQGradient A10 system (Millipore, Billerica, USA).

The reference standard of modafinil (lot 1300-075A1) was purchased from TLC Pharmaceutical Standards Ltd. (Aurora, Ontario, Canada) and solubilised in methanol at a final concentration of $1 \mathrm{mg} / \mathrm{mL}$

DMSO- $d_{6}\left(99.9 \%\right.$ D) and $\mathrm{D}_{2} \mathrm{O}(99.9 \% \mathrm{D})$ were from SigmaAldrich (Steinheim, Germany). 3-(Trimethylsilyl)-1-propanesulfonic acid $-d_{6}$ sodium salt $(98 \% \mathrm{D})$ was purchased from Isotec (Miamisburg, $\mathrm{OH}$, USA).

\section{Sample preparation for MS}

Prior to analysis, sample package, labeling and the appearance of the tablet or capsule to be analyzed were documented. Next, a number of units were then taken, depending on the number of units available for analysis, and weighed on an analytical balance to obtain a mean weight. The sum of these units were ground (in case of tablets) and mixed or capsules were opened mixed and the pulverized material was used for sample preparation followed by subsequent GC-MS and LC-MS/MS analysis. In agreement with Johansson et al. [17] the general sample preparation for GC-MS and LC-MS/MS consisted of a methanol extraction. Briefly, $30 \mathrm{mg}$ of the mixed sample is solubilized in $10 \mathrm{ml} \mathrm{MeOH}$ and sonicated for 15 minutes and passed through a $0.2 \mu \mathrm{m}$ PTFE filter prior to injection into the two different MS systems.

\section{GC-MS}

The analyses were performed on an Agilent 7890A gas chromatograph coupled to an Agilent 5975 mass selective detector. The Column VF-5ms+10 m EZ-guard was purchased from Agilent technologies (Santa Clara, CA, USA).

Full automation was achieved using Agilent MSD ChemStation data acquisition and data handling software. Injections were made in the split mode $(3.3: 1)$ at an injection port temperature of $280^{\circ} \mathrm{C}$. The column oven temperature was initially set to $80^{\circ} \mathrm{C}$ for $2 \mathrm{~min}$ and then raised at $15^{\circ} \mathrm{C} / \mathrm{min}$ to $280^{\circ} \mathrm{C}$ and held for $17 \mathrm{~min}$, followed by a raise of $10^{\circ} \mathrm{C} / \mathrm{min}$ to $310^{\circ} \mathrm{C}$ and held for 20 minutes. The total run time was $55 \mathrm{~min}$. The temperatures of the interface, the source and the quad interface were 280,230 and $150^{\circ} \mathrm{C}$, respectively. The solvents were separated on an Agilent column $(30 \mathrm{~m} \times 0.25 \mathrm{~mm} \times 0.25 \mu \mathrm{m}$ film thickness). High-purity helium was used as the carrier gas with flow rate of $1 \mathrm{~mL} / \mathrm{min}$ and the column head pressure was set at $93.169 \mathrm{kPa}$. The mass spectrometer was operated with electron ionisation with electron energy of $70 \mathrm{eV}$, a source temperature of $230^{\circ} \mathrm{C}$ and an ion multiplier gain of $1.765 \mathrm{kV}$. Data were acquired in full scan mode of $\mathrm{m} / \mathrm{z} 25$ to 600

\section{LC-MS/MS}

The solubilised suspected sample was first subjected to analysis on a Dionex UltiMate 3000 Rapid Separation LC (RSLC) system (Thermo Scientific, Sunnyvale, CA, USA) coupled to an amaZon ${ }^{\text {tx }}$ speed ETD mass spectrometer (Bruker Daltonics, Bremen, Germany). The instrument system was calibrated using the manufacturer's calibration mixture, and the mass accuracy was determined to be $<0.1 \mathrm{Da}$ during the period of analysis. A sample volume of $1 \mu \mathrm{L}$ was injected in the system. The chromatographic separation was performed at $45^{\circ} \mathrm{C}$ on an Acquity UPLC BEH C ${ }_{18}$ Column $(150 \times 2.1 \mathrm{~mm}, 1.7 \mu \mathrm{m}$ particle size $)$ (Waters, Milford, MA, USA) with a mobile phase consisting of $0.1 \%$ formic acid in water (A) and $0.1 \%$ formic acid in acetonitrile (B). A general LC method, suitable for rapid screening of suspected samples was used. A linear gradient from 1\% B to $99 \%$ B was accomplished in $9 \mathrm{~min}$, followed by an isocratic elution for $2 \mathrm{~min}$ and $2 \mathrm{~min}$ at $1 \% \mathrm{~B}$. The flow rate was $0.5 \mathrm{~mL} / \mathrm{min}$.

The mass spectrometer settings were similar to what has been previously described [18]. Small adjustments were made to the mass range $(50-1000 \mathrm{~m} / \mathrm{z})$ and the smart parameter setting $(\mathrm{m} / \mathrm{z} 475)$. The LC and MS data were analysed by Compass Data Analysis 4.2 (Bruker Daltonics, Bremen, Germany) and the LC-MS/MS spectra were compared to different libraries, including the in-house library, enclosing a total of about $5000 \mathrm{MS} / \mathrm{MS}$ spectra and which also contains MS/MS spectra of modafinil and the modafinil analogues, hydrafinil and eugerafinil. A $0.30 \mathrm{Da}$ precursor tolerance for MS spectra and MS/MS spectra were allowed.

\section{Qualitative and quantitative NMR analysis}

In order to obtain NMR (nuclear magnetic resonance) spectra of the supplement, $2.4 \mathrm{mg}$ of the mixture of capsule composite was solubilized in $1 \mathrm{~mL}$ of DMSO- $d_{6}$, sonicated for 20 minutes and centrifuged. The supernatant was then analysed by a range of $1 \mathrm{D}\left({ }^{1} \mathrm{H}\right.$, ${ }^{13} \mathrm{C}$, DEPT135 and DEPT90) and 2D (COSY, HSQC and HMBC) NMR experiments. The NMR experiments were performed on a Bruker DRX-400 (Rheinstetten, Germany) operating at $400 \mathrm{MHz}$ for ${ }^{1} \mathrm{H}$ and at $100 \mathrm{MHz}$ for ${ }^{13} \mathrm{C}$, equipped with a $5 \mathrm{~mm}$ dual ${ }^{1} \mathrm{H} /{ }^{13} \mathrm{C}$ probe using standard Bruker pulse sequences. The spectra were processed with Topspin version 1.3. In order to quantify the amount of adrafinil per capsule and to verify whether the statement on the label, that each capsule contains $300 \mathrm{mg}$ adrafinil, is correct, a quantitative ${ }^{1} \mathrm{H}$ NMR experiment was performed in quadruplicate. Briefly, $0.9 \mathrm{mg}$ of the content of the capsules was dissolved in $1.95 \mathrm{~mL}$ of $\mathrm{D}_{2} \mathrm{O}$ followed by $30 \mathrm{~min}$ sonication. Also a solution of $1.6 \mathrm{mg}$ of 3-(Trimethylsilyl)-1propanesulfonic acid- $d_{6}$ sodium salt in $1.00 \mathrm{~mL}$ of $\mathrm{D}_{2} \mathrm{O}$ was prepared and $50 \mu \mathrm{L}$ of this internal standard solution was added to the solution of the suspected adrafinil sample.

\section{Results and Discussion}

\section{Sample preparation and general analytical strategy when reference standard is available}

As a general way of working, food supplements suspected to contain an illegal pharmaceutical product are first described and photographed. Next, in accordance with Johansson et al. [17], several tablets or capsules are used for sample preparation however, the number of samples tested has to be balanced with the time and resources spent on each case. In general half of the units are mixed prior to solubilisation, however, in case that more than 20 units are present, one fourth of the number of units is weighted and mixed prior to solubilisation and analysis by GC-MS and LC-MS/MS. Next, the spectra obtained from GC-MS are generally compared to the NIST 11 mass spectral database, while the LC-MS and LC-MS/MS spectra are compared to different libraries, including an in-house library consisting of a diverse plethora of molecules for which a reference standard is available. However, when the screening methodology indicates the 
Citation: Vanhee C, Tuenter E, Kamugisha A, Canfyn M, Moens G, et al.(2017) Identification and Quantification Methodology for the Analysis of Suspected Illegal Dietary Supplements: Reference Standard or no Reference Standard, that's the Question. J Forensic Toxicol Pharmacol 6:2.

presence of a compound that is not frequently encountered by our OMCL lab, a reference standard is injected to verify the outcome of the query. In the latter case, the compound is considered a match when the criteria of the European council directive 96/23/EC $\mathrm{E}^{13}$ are met. Concretely, the retention time falls into the $2.5 \%$ error time interval and the most intense product ions must be found in the MS (GC-MS and LC-MS) and/or the most intense fragment ions must be found in the MS/MS spectrum (LC-MS/MS). Once the identity of the molecule is established, a relative quantification can be executed by means of (ultra)-high-performance liquid chromatography-diode array detector ((U)HPLC-DAD), (U)HPLC-MS or GC-MS. This accredited approach has been used for the analysis of more than a thousand food supplements and suspected illegal medicines. In the last 2 years, over 400 suspicious food supplements were chemically analysed in our OMCL laboratory and at least in 80 samples an illegal drug or research chemical was found present in an pharmacological active dose. The vast majority of the medicines encountered in those samples belong to the three 'classical' categories, including sexual enhancers (e.g. PDE-5 inhibitors and the female "Viagra" Flibanserin), weight loss enhancers occasionally accompanied with an anti-depressant (e.g. sibutramine, phenolphthalein, sibutramine and fluoxetine or venlafaxine) and sports performance enhancers (e.g. selective androgen receptors (SARMs), anabolic-androgenic steroids (AAS)). However, occasionally, drugs belonging to other classes, including the neural enhancer pramicetam, the small research peptide epitalon, the psychoactive pregabalin and alkaloid mytragynine have been identified in food supplements. However, sometimes the identification and relative quantification of the possible active pharmaceutical ingredient is not so straight forward when no reference standard is available.

\section{Sample preparation and general analytical strategy when no reference standard is available}

The suspected sample same went to procedure as described in the previous chapter. Pictures were taken of the brown plastic bottle marked "Adrafinil", which contained 30 transparent capsules filled with a pale brown coloured powder. Furthermore, the label stated the presence of $300 \mathrm{mg}$ of adrafinil per capsule. The average weight of the content of the 7 capsules was determined and corresponds to $376.7 \mathrm{mg}$ (RSD of 2.77\%). It stands to reason that compounds present in high concentrations could produce saturated MS signals when injecting a suspected solubilized sample at a concentration of $10 \mathrm{mg} /$ $\mathrm{ml}$ [17]. Therefore, the content of 7 capsules was mixed and $30 \mathrm{mg}$ of this mixture was solubilised in $10 \mathrm{~mL}$ of methanol and subjected to GC-MS and LC-MS/MS analysis.

Unfortunately, subsequent GC-MS analysis showed that the molecule was thermally degraded and resulted mainly in 3 different peaks (Figure 1A). Two of these peaks, eluting at $9.5 \mathrm{~min}$ and $11.2 \mathrm{~min}$ were, according to the NIST 11 mass spectral database, corresponding respectively to diphenylmethane and alpha-phenyl-benzenemethanol (Figure 1B). The additional third peak, eluting at $17.5 \mathrm{~min}$ did not result in a confident hit using the NIST 11 mass spectral database, but could reflect the presence of 1,1,2,2-tetraphenylethane as has been recently reported [19] since the characteristic ions of this compound and the fragments generated by this compound are all present at this time point (Figure 1C). A similar pattern was also found for modafinil (data not shown). The results obtained with modafinil and the unknown sample is in accordance with recent reported findings on thermal degradation of modafinil and its prodrug adrafinil. However, this thermal degradation makes it impossible to gain the required identification points as required by European council directive 96/23/ EC [13].

Simultaneously, also LC-MS/MS analysis was performed on the unknown sample and the reference standard of modafinil. The LCMS analysis of the unknown sample showed the presence of multiple single charged ions at a retention time of 5.6 minutes (Figure 2A). The precursor ion with an $\mathrm{m} / \mathrm{z}$ ratio of 166.75 could correspond to a diphenylmethyl cation (theoretical $\mathrm{m} / z$ 167.08) as mentioned in Lu et al. [20], and was also observed for modafinil. The ion with $\mathrm{m} / \mathrm{z}$ 311.8 could correspond to $[\mathrm{M}+\mathrm{Na}]^{1+}$ with theoretical $\mathrm{m} / z$ 312.07, the ion with $m / z 600.99$ could correspond to $[2 \mathrm{M}+\mathrm{Na}]^{1+}$ with theoretical $\mathrm{m} / z 601.14$ and the ion with $\mathrm{m} / z 455.95$ could correspond to [M+ $\left.\mathrm{Ph}_{2} \mathrm{CH}+\right]^{1+}$ with theoretical $\mathrm{m} / z$ 456.16. Interestingly, a similar pattern was observed for modafinil, when analysed under the same LC-MS/MS conditions (Figure 2B). Furthermore, the MS/MS spectra of the precursor $m / z 600.99$ resulted in a complete disappearance of this precursor and the generation of a fragment ion with $\mathrm{m} / z$ 311.8, while the MS/MS spectra of the precursor with $\mathrm{m} / z 311.8$ generated mainly an ion with $m / z 144.70$. The latter is probably a sodium adduct on the alkylsulfinyl side chain. Moreover, the precursor ion with $\mathrm{m} / \mathrm{z}$ 167.08 also generated a product ion with $\mathrm{m} / z 152.00$ (Figure 2C) which was also in agreement with the observations made by $\mathrm{Lu}$ et al. [20]. However, with the lack of any reference standard, again no identification points can be attributed to the spectra.

Based on the information mentioned on the sample and the GC-MS and LC-MS/MS spectra compared to what is known in the literature, the presence of adrafinil in the suspected food supplement can be assumed. However, the presence of this compound cannot unambiguously be proven and for sure will not hold up in court. Therefore, NMR structure elucidation experiments were performed on the sample to identify the major constituent of the capsules. Similar approaches have been used by other OMCLs to confirm the presence of the potential doping peptide GHRP-6 [21], the presence of aceclofenac in illegal Adderall tablets [22] or to screen for pharmacologically active substances in weight-loss supplements [23]. Additionally this methodology is also routinely by another OMCL as an expensive independent alternative to high resolution LC-MS [17].

Both 1D and 2D NMR spectra were recorded and the respective spectroscopic data are shown in Table 1. The obtained NMR spectra are provided as Supporting Information. From the $13 \mathrm{C}$ spectrum, ten different signals could be distinguished. Comparing this spectrum to the DEPT135 and DEPT90 spectra, it could be deduced that three of those signals represented quaternary carbon atoms, one represented a tertiary carbon and the others were secondary carbons. The HSQC spectrum revealed that the tertiary carbon was bound to two protons with $\delta \mathrm{H} 3.33 \mathrm{ppm}$ and $3.07 \mathrm{ppm}$. Those proton signals appeared as doublets $(\mathrm{J}=13.3 \mathrm{~Hz})$ and did not show any cross peaks in the COSY spectrum, but showed correlations with $\delta C 161.1 \mathrm{ppm}$ and $\delta \mathrm{C} 69.0$ $\mathrm{ppm}$ in the HMBC spectrum. Indeed, adrafinil contains one tertiary carbon (Figure 3), C-2, and the signals with $\delta \mathrm{C} 161.1 \mathrm{ppm}$ and $\delta \mathrm{C}$ 69.0 ppm could be assigned to C-1 and C-3 respectively.

The carbon signal at $161.1 \mathrm{ppm}$ also showed an $\mathrm{HMBC}$ cross peak with a proton signal at $10.80 \mathrm{ppm}$. This proton was not bound to a carbon atom, since no cross peak was present in the HSQC spectrum. This was also the case for the proton signal at $9.12 \mathrm{ppm}$. Moreover, those two proton signals showed a cross peak in the COSY spectrum and the latter proton signal showed a correlation with $\delta C 161.1$ too, although the intensity of this correlation was very weak. Taken together these data, and after comparison to data reported by Kaczor 
Citation: Vanhee C, Tuenter E, Kamugisha A, Canfyn M, Moens G, et al.(2017) Identification and Quantification Methodology for the Analysis of Suspected Illegal Dietary Supplements: Reference Standard or no Reference Standard, that's the Question. J Forensic Toxicol Pharmacol 6:2.

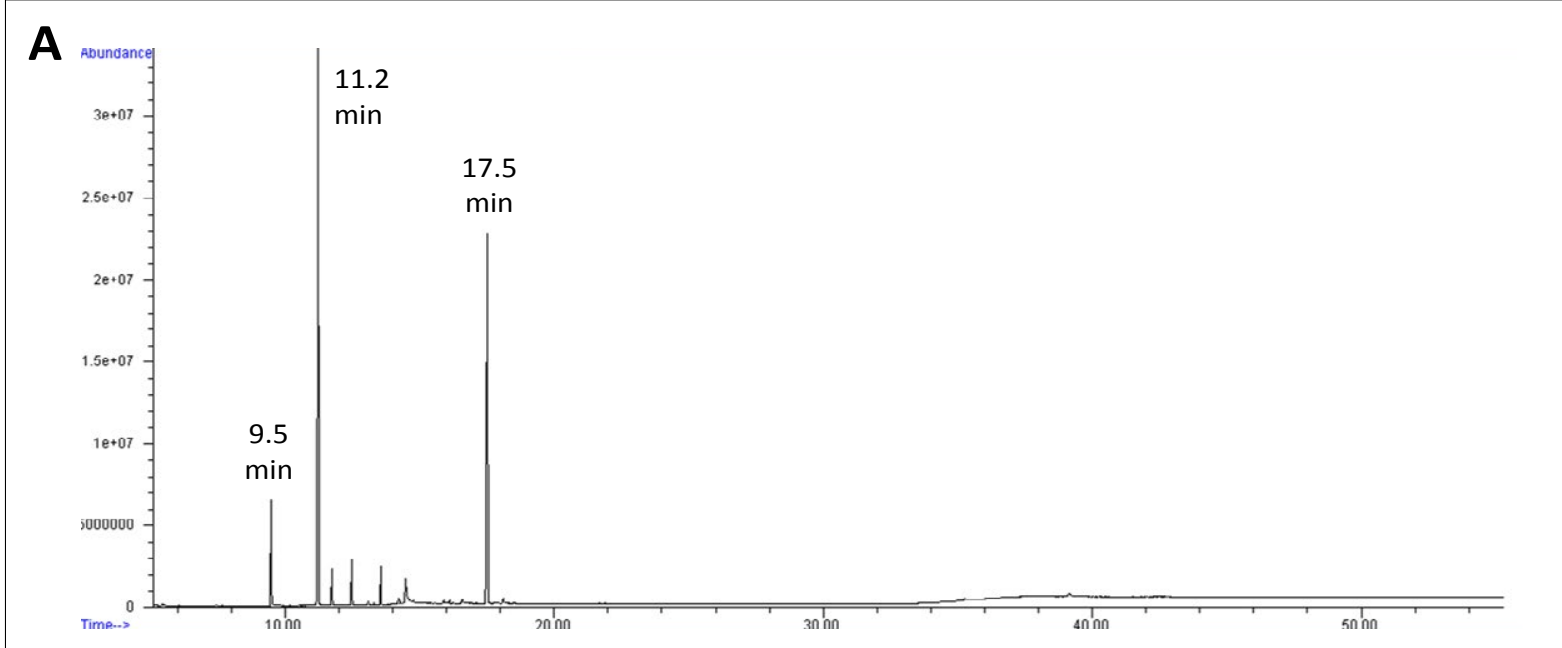

B

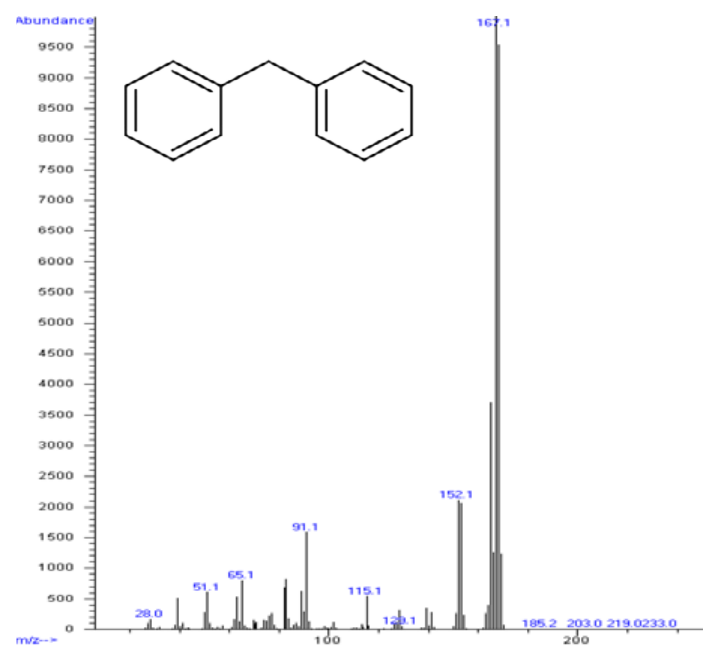

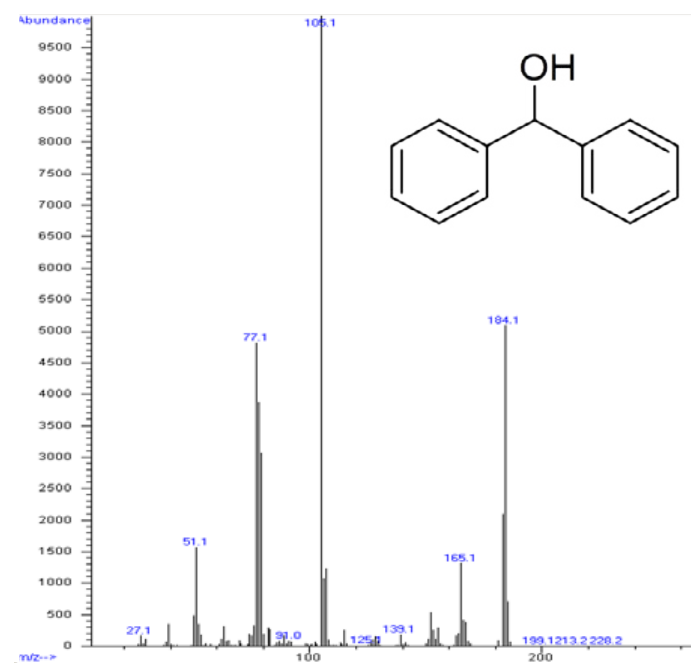

C

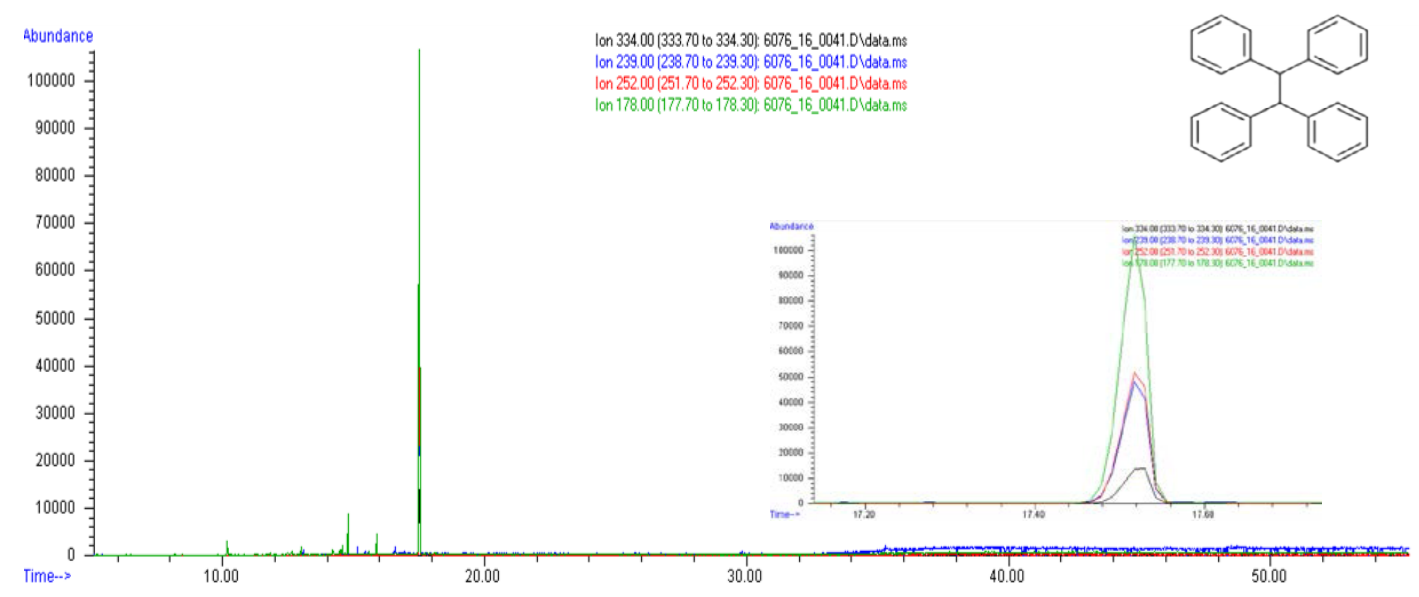

Figure 1: (A) Total ion chromatogram, obtained by GC-MS of a full scan mass spectrum of the unknown sample, (B) showing the presence of 3 intense peaks eluting at $9.5,11.5$ and 17.5 minutes. The MS spectrum of the first two peaks corresponds respectively to diphenylmethane and diphenylmethanol according to queries performed against the NIST database. (C) The third peak reflect the presence of 1,1,2,2-tetraphenylethane since extracted ion chromatograms display the presence of the characteristic ions of this compound. 
Citation: Vanhee C, Tuenter E, Kamugisha A, Canfyn M, Moens G, et al.(2017) Identification and Quantification Methodology for the Analysis of Suspected Illegal Dietary Supplements: Reference Standard or no Reference Standard, that's the Question. J Forensic Toxicol Pharmacol 6:2.

A

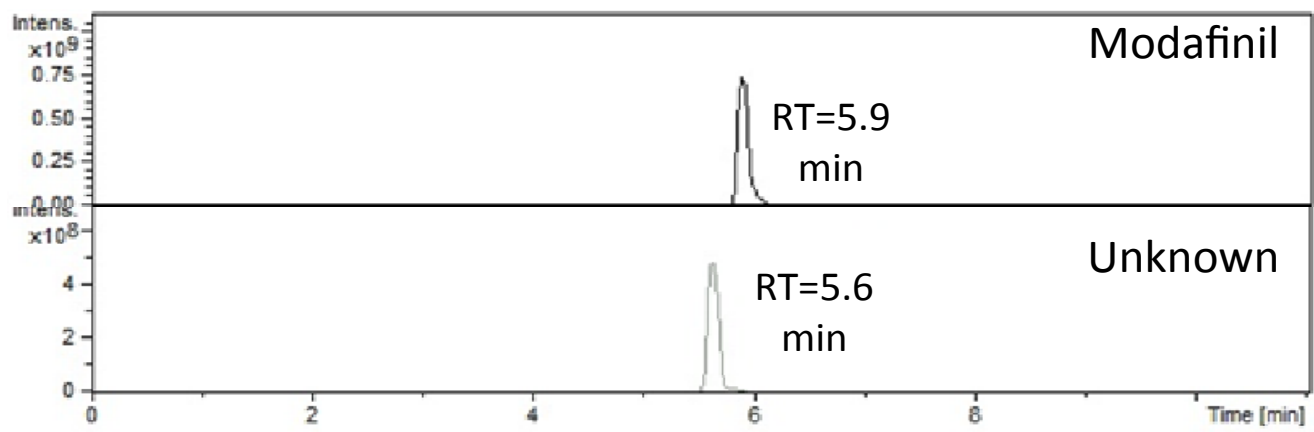

B

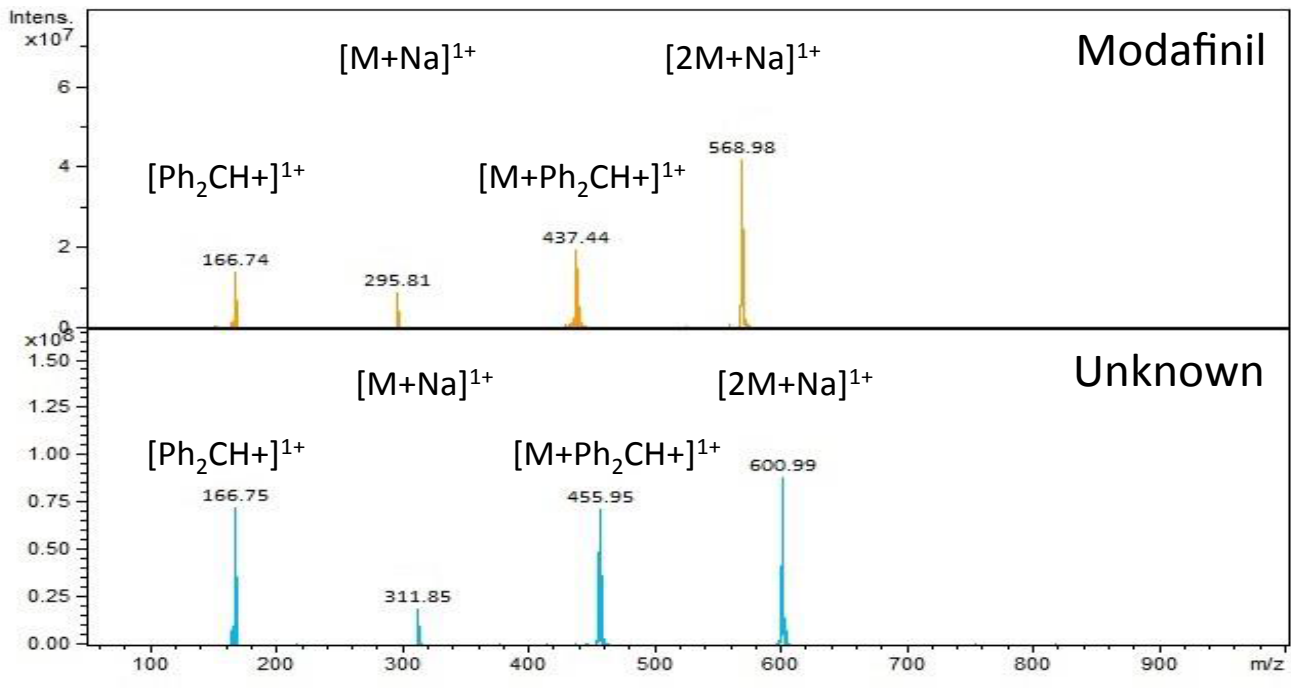

C

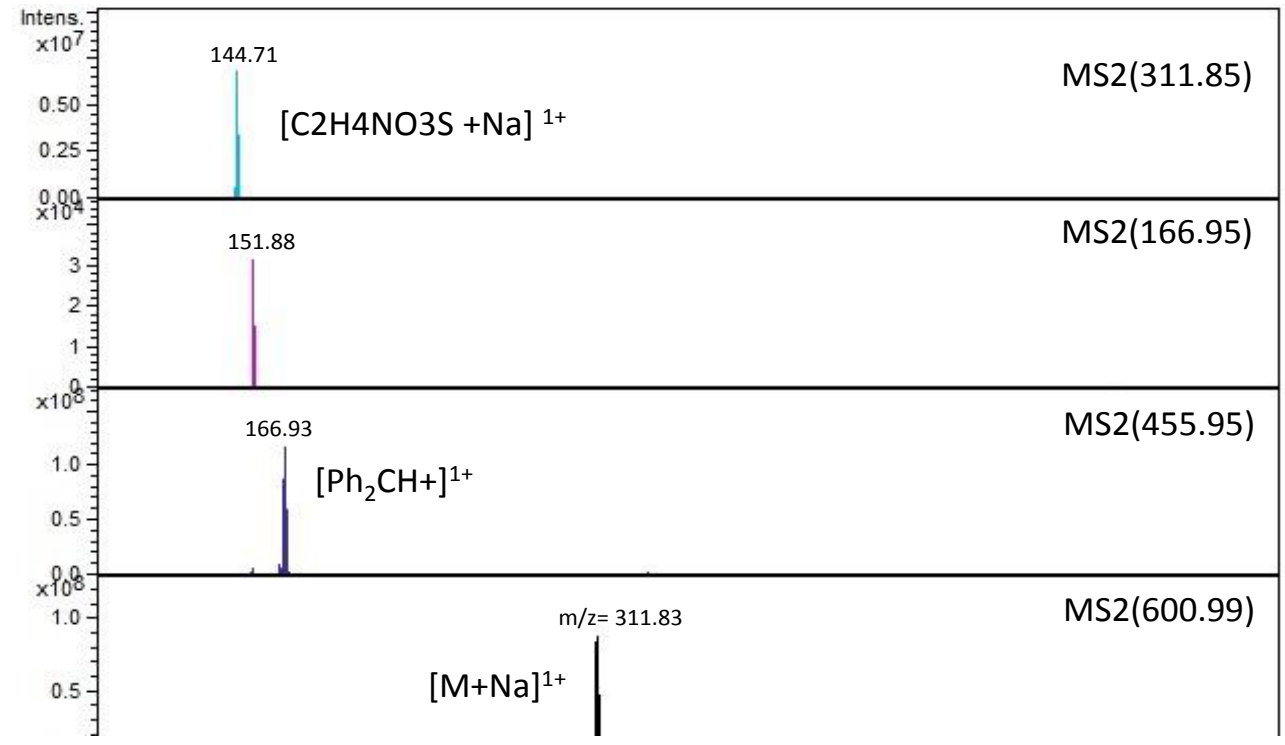

Figure 2: Total ion chromatograms, obtained by LC-MS/MS, of a full scan mass spectrum of standards of modafinil and the unknown sample (A). Full scan low resolution MS/MS spectrum of modafinil (retention time $=5.9 \mathrm{~min}$ ) and the component present in the unknown sample, eluting at 5.6 minutes $(B)$. Tentative identifications are assigned. M: neutral mass of a given molecular species; $\mathrm{Ph}_{2} \mathrm{CH}+$ : diphenylmethyl cation with $\mathrm{m} / \mathrm{z} 166.7$. The MS2 product ions originating from a certain precursor ion present in the unknown sample are depicted in $\mathrm{C}$. 
Citation: Vanhee C, Tuenter E, Kamugisha A, Canfyn M, Moens G, et al.(2017) Identification and Quantification Methodology for the Analysis of Suspected Illegal Dietary Supplements: Reference Standard or no Reference Standard, that's the Question. J Forensic Toxicol Pharmacol 6:2.

Table 1: ${ }^{1} \mathrm{H}$ and ${ }^{13} \mathrm{C}$ NMR spectroscopic data for the supplement, aspectra were recorded in DMSO- ${ }_{6}$.

\begin{tabular}{|c|c|c|}
\hline \multirow{2}{*}{ Position } & \multirow{2}{*}{$\delta_{c}$ in ppm, (type) } & \multirow{2}{*}{$\begin{array}{l}d_{H} \text { in ppm, Multiplicity } \\
(J \text { in Hz) }\end{array}$} \\
\hline & & \\
\hline $\mathrm{OH}$ & - & $9.12, \mathrm{~s}$ \\
\hline $\mathrm{NH}$ & - & $10.7, \mathrm{~s}$ \\
\hline 1 & $161.1,(C)$ & \\
\hline $2 a$ & 53.8, $\left(\mathrm{CH}_{2}\right)$ & 3.07, d (13.3) \\
\hline $2 b$ & & 3.33, d (13.3) \\
\hline 3 & 69.0, $(\mathrm{CH})$ & $5.39, \mathrm{~s}$ \\
\hline 1', 1" & $137.0,134.8,(\mathrm{C})$ & - \\
\hline $2^{\prime}, 6^{\prime}$ or $2^{\prime \prime} 6^{\prime \prime}$ & $129.7,128.5(\mathrm{CH})$ & $7.51^{\star}, 7.52^{*}$ \\
\hline $3^{\prime}, 5^{\prime}$ or $3^{\prime \prime}, 5^{\prime \prime}$ & $129.0,128.5(\mathrm{CH})$ & $7.42^{\star}, 7.41^{*}$ \\
\hline $4^{\prime}$ or $4^{\prime \prime}$ & $128.0,127.9(\mathrm{CH})$ & $7.36^{*}$ \\
\hline
\end{tabular}

A

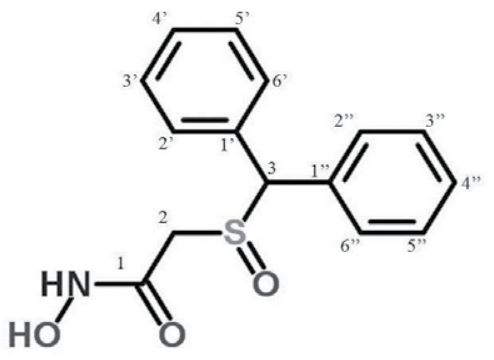

Adrafinil
B

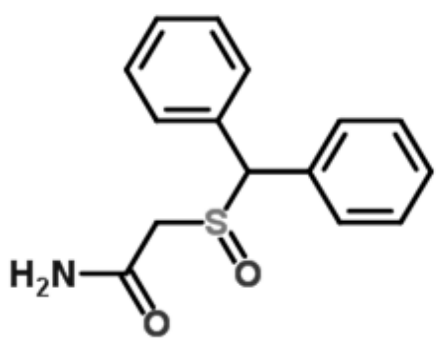

Modafinil

Figure 3: Chemical structures of modafinil and adrafinil.

et al. [23], who described the 1H NMR shifts for salicylohydroxamic acid, a compound containing a hydroxamic acid functional group (R-CO-NR'-OH) which is also present in adrafinil, the signal at 10.80 ppm was assigned to the $\mathrm{N}-\mathrm{H}$ proton and the signal with $\delta 9.12 \mathrm{ppm}$ was assigned to the $\mathrm{O}-\mathrm{H}$ proton [24].

The remaining NMR signals represent aromatic proton and carbon atoms. Due to the high amount of signals, with similar chemical shift values, an overlap of signals is seen in this region of the ${ }^{1} \mathrm{H},{ }^{13} \mathrm{C}$ and HSQC spectrum. It can be deduced however, that two phenyl moieties are present and they are connected to C-3, as deduced form the HMBC spectrum. All chemical shift values that were found for the supplement are in accordance to the ${ }^{1} \mathrm{H}$ and ${ }^{13} \mathrm{C}$ NMR data reported for adrafinil by Osorio-Lozada et al. [25] and thus confirm the presence of adrafinil in the capsules. Since no other signals than those coinciding with the presence of Adrafinil are found, we can assume that this compound is the main compound present in the mixture. Therefore, by using a quantitative $1 \mathrm{H}$ NMR experiment, we can estimate the amount of adrafinil per capsule in order to verify if potential pharmacological active doses were present. In order to do so, an internal standard was added to the solubilised suspected sample. The amount of the internal standard (IS) in the sample was $0.35 \pm 0.01 \mu \mathrm{moL}$. In case the content of the capsules would consist solely of adrafinil, $3.49 ; 3.59 ; 2.70$ and $2.94 \mu \mathrm{mol}$ of this compound would be present in the four NMR samples respectively. In the obtained $1 \mathrm{H}$ spectra, the integral corresponding to the nine protons of the trimethylsilyl group of the IS was set as 1.00 . Thus, a theoretical peak surface area of $1.08 ; 1.16 ; 0.87$ and 0.97 would be expected for the $\mathrm{H}-3$ of adrafinil, at $5.43 \mathrm{ppm}$ and the total integral of the ten aromatic proton signals would be expected to be ten times as high. The percentage of adrafinil in the supplement can now be calculated, based on the ratio of the obtained peak surface area and the theoretical peak surface area and was found to be $79.8 \pm 8.9 \%$. The average weight of the capsules is $376.7 \mathrm{mg}$ and thus each capsule contains $300.6 \pm 33.6 \mathrm{mg}$ of adrafinil. Thus, the statement on the label of the samples, that each capsule contains $300 \mathrm{mg}$ of adrafinil, is in correspondence to the obtained result.

According to previous reports, a dose of $100 \mathrm{mg}$ of modafinil can be used to treat patients suffering from narcolepsy [26]. Although there is limited data available on the extent of which adrafinil is converted into modafinil, a dose of $300 \mathrm{mg}$ of adrafinil, is a pharmacological relevant quantity.

\section{Conclusion}

A food supplement suspected to contain adrafinil was submitted by the FASFC for analysis in our laboratory. Based on the interpretation of our successful classical strategy (GC-MS and LC-MS/MS) no unambiguous identification was possible hence no reference standard was available. Therefore, the samples was subsequently analysed by a range of $1 \mathrm{D}\left({ }^{1} \mathrm{H},{ }^{13} \mathrm{C}, \mathrm{DEPT} 135\right.$ and DEPT 90$)$ and $2 \mathrm{D}$ (COSY, HSQC and HMBC) NMR experiments, which confirmed the presence of the modafinil analogue adrafinil in those capsules. The use of this chemical in food supplements is not approved in the EU, since it is considered a medicinal product. Quantitative NMR analysis indicated that, each capsule contains approximately $300 \mathrm{mg}$ adrafinil, which is equivalent to the amount of adrafinil present in the medicine that was taken of the market. Furthermore the prescription limit for people with liver problems is currently set at $100 \mathrm{mg}$ of Modafinil a day. Consequently, the hepatic metabolisation of $300 \mathrm{mg}$ of this prodrug could lead to more hepatic stress and can have some detrimental effects for liver patients, including liver transplants, or even fatalities as reported in the grey literature. Startlingly this product can still 
Citation: Vanhee C, Tuenter E, Kamugisha A, Canfyn M, Moens G, et al.(2017) Identification and Quantification Methodology for the Analysis of Suspected Illegal Dietary Supplements: Reference Standard or no Reference Standard, that's the Question. J Forensic Toxicol Pharmacol 6:2.

be bought online and is promoted as a natural and safe nootropic equivalent to Adderall. Furthermore, in 2017 already several food supplements analysed by our lab were positive for the presence of members of the nootropic racetam family and even the research nootropic N-Phenylacetyl-L-prolylglycine ethyl ester, known online as noopept, has been encountered.

\section{Acknowledgement}

We gratefully acknowledge the FAMHP and FASFC.

\section{References}

1. Kuszak AJ, Hopp DC, Williamson JS, Betz JM, Sorkin BC (2016) Approaches by the U.S. national institutes of health to support rigorous scientific research on dietary supplements and natural products. Drug Test Anal.

2. Rocha T, Amaral JS, Oliveira PBPP (2016) Adulteration of dietary supplements by the illegal addition of synthetic drugs: A review. Compr Rev Food Sci F 15: 43-62.

3. Chatham-Stephens K, Taylor E, Chang A, Peterson A, Daniel J, et al. (2016) Hepatotoxicity associated with weight loss or sports dietary supplements, including OxyELITE Pro ${ }^{\mathrm{TM}}$. Drug Test Anal.

4. Gualtieri FJ (2016) Unifi nootropics from the lab to the web: a story of academic (and industrial) shortcomings. Enzyme Inhib Med Chem.

5. Reepmeyer JC, Woodruff JT, d'Avignon DA (2007) Structure elucidation of a novel analogue of sildenafil detected as an adulterant in an herbal dietary supplement 43: 1615-1621.

6. Venhuis BJ, Zomer G, Hamzink M, Meiring HD, Aubin Y, et al. (2011) The identification of a nitrosated prodrug of the PDE-5 inhibitor aildenafil in a dietary supplement: a Viagra with a pop. J Pharm Biomed Anal.

7. Venhuis BJ, Keizers P, van Riel A, de Kaste D (2014) A cocktail of synthetic stimulants found in a dietary supplement associated with serious adverse events. Drug Test Anal 6: 578-581.

8. Van Hunsel F, Venhuis BJ, Keizers PH, Kant A (2015) A 'natural' weight loss product containing sibutramine. Drug Test Anal 8: 311-314.

9. Rebiere H, Guinot P, Civade C, Bonnet PA, Nicolas A (2012) Detection of hazardous weight-loss substances in adulterated slimming formulations using ultra-high-pressure liquid chromatography with diode-array detection. Food Addit Contam Part A Chem Anal Control Expo Risk Assess.

10. Cohen PA, Avula B, Venhuis B, Travis JC, Wang Y-H, et al. (2017) Pharmaceutical doses of the banned stimulant oxilofrine found in dietary supplements sold in the USA. Drug Test Anal 9: 135- 142

11. Geldof L, Pozo OJ, Lootens L, Morthier W, Van Eenoo P, et al. (2017) In vitro metabolism study of a black market product containing SARM LGD-4033. Drug Test Anal 9: 168-178.

12. Cohen PA, Venhuis BJ, Brandt SD (2016) Advancing supplement science: challenges and solutions. Drug Test Anal 8: e1-e3.

13. European commission decision of 12 August 2002 implementing Council Directive 96/23/EC concerning the performance of analytical methods and the interpretation of results.

14. Information point on the files discussed in the AMM Committee.

15. Thobois S, Xie J, Mollion H, Benatru I, Broussolle E (2004) Adrafinil-induced orofacial dyskinesia. Mov Disord.

16. European council directive 2001/83/EC of the European parliament and of the council of 6 November 2001 on the community code relating to medicinal products for human use.

17. Johansson M, Fransson D, Rundlöf T, Huynh NH, Arvidsson T (2014) A general analytical platform and strategy in search for illegal drugs. J Pharm Biomed Anal.

18. Vanhee C, Janvier S, Desmedt B, Moens G, Deconinck E, et al. (2015) Analysis of illegal peptide biopharmaceuticals frequently encountered by controlling agencies. Talanta.

19. Dowling G, Kavanagh PV, Talbot B, O'Brien J, Hessman G, et al. (2016) Outsmarted by nootropics? An investigation into the thermal degradation of modafinil, modafinic acid, adrafinil, CRL-40,940 and CRL-40,941 in the GC injector: formation of 1,1,2,2-tetraphenylethane and its tetra fluoro analog Drug Test Analysis.

20. Lu J, Wang X, Yang S, Liu X, Qin Y, et al. (2009) Doping control analysis for adrafinil and its major metabolites in human urine. Rapid Commun Mass Spectrom 23: 1592-1600.

21. Gaudiano MC, Valvo L, Borioni A (2014) Identification and quantification of the doping agent GHRP-2 in seized unlabelled vials by NMR and MS: a casereport. Drug Test Anal 6: 295-300.

22. Gaudiano MC, Borioni A, Antoniella E, Valvo L (2016) Counterfeit adderal containing aceclofenac from internet pharmacies. J Forensic Sci 61: 11261130.

23. Monakhova YB, Kuballa T, Löbell-Behrends S, Hengen J, Maixner S, et al (2012) $1 \mathrm{H}$ NMR screening of pharmacologically active substances in weightloss supplements being sold online. Lebensmittelchemie 66: 147-150.

24. Kaczor A, Proniewicz L (2003) NMR spectra of salicylohydroxamic acid in DMSO-d6 solution: a DFT study. J Mol Struc-Theochem 640: 133-141.

25. Osorio-Lozada A, Prisinzano T, Olivo HF (2004) Synthesis and determination of the absolute stereochemistry of the enantiomers of adrafinil and modafinil. Tetrahedron-Asymmetr.

26. Thorpy MJ, Dauvilliers $Y$ (2015) Clinical and practical considerations in the pharmacologic management of narcolepsy. Sleep Med 16: 9-18.

\section{Author Affiliations}

Top

${ }^{1}$ Division of food, medicines and consumer safety, section medicinal products, Scientific Institute of Public Health (WIV-ISP), Belgium

${ }^{2}$ Natural Products \& Food Research and Analysis (NatuRA), Department of Pharmaceutical Sciences, University of Antwerp, Antwerp, Belgium

Submit your next manuscript and get advantages of SciTechnol submissions
* 80 Journals
* 21 Day rapid review process
* 3000 Editorial tean
- 5 Million readers
- More than 5000 facebook
- Quality and quick review processing through Editorial Manager System

Submit your next manuscript at • www.scitechnol.com/submission 